\title{
Van grensbrug naar stadsbrug
}

AUTEUR \& FOTOGRAFIE Bianca Szytniewski

\section{Tegenwoordig is de 'Brug der Vriendschap' tussen Frankfurt en Slubice een rustige grensovergang, waar de bewoners op hun gemak de brug overste- ken voor een wandeling, een bezoek aan een res- taurant of kapper of een dagje winkelen. Dat is echter niet altijd zo geweest. Kan de grensbrug gezien worden als een borderscape in de zin van een verbinding die grensoverschrijdende contacten en mobiliteit schept?}

Een uur ten oosten van Berlijn ligt de grensstad Frankfurt, aan de rivier de Oder. Een stad die al in de middeleeuwen gesticht is, maar vooral na de Tweede Wereldoorlog bekend is geworden als een gescheiden stad met de stadskern in Duitsland en de voormalige Dammvorstadt, tegenwoordig Slubice, in Polen. De grensbrug, die in 1952 de naam 'Brug der Vriendschap' kreeg, is in het verleden niet alleen gebruikt om Frankfurt en Slubice met elkaar te verbinden, maar ook van elkaar te scheiden.

\section{Brug tussen twee landen}

Bruggen symboliseren verbindingen tussen twee zijden die eerder van elkaar gescheiden waren. De brug tussen Frankfurt en Slubice symboliseert echter meer dan alleen een verbinding tussen de twee voormalige stadsdelen: het is ook een verbinding tussen twee volken met eigen nationale kenmerken in taal, cultuur, sociale omgang, politiek en economie. Bruggen creëren nieuwe ruimtes, maar verruimen ook bestaande ruimtes, zoals socioloog en filosoof Georg Simmel terecht opmerkt in zijn essay 'Bridge and Door'. Het fysieke karakter van de brug tussen Frankfurt en Slubice kan nieuwe mogelijkheden voor grensoverschrijdende contacten en mobiliteit scheppen, waarbij de andere kant van de brug een onderdeel van het dagelijkse leven wordt. Dit hoeft echter niet altijd het geval te zijn. De manier waarop wordt omgegaan met een grensbrug als borderscape hangt af van de betekenis die aan de grens wordt toegekend. Grenzen kunnen open of gesloten zijn en worden door elk individu anders beleefd. Verschillen tussen landen kunnen bewoners van een grensstad bijvoorbeeld aantrekken om de brug over te steken en het onbekende te ontdekken. Een gevoel van onbekendheid ten opzichte van de andere kant van de grens kan mensen echter ook afschrikken en juist tot minder grensoverschrijdende contacten leiden. In dit artikel zal de brug tussen Frankfurt en Slubice centraal staan. Zowel basisliteratuur als observaties en krantenartikelen van twee regionale kranten zijn gebruikt om een beeld te scheppen van de historische ontwikkelingen rondom de stadsbrug, waarbij dieper in zal worden gegaan op de rol van de brug in het genereren van contacten en mobiliteit tussen beide zijden van de Oder.

\section{Nieuwsgierige blik naar de overzijde}

Met het einde van de Tweede Wereldoorlog veranderde de grenssituatie tussen Duitsland en Polen. Onder druk van de Sovjet-Unie kwamen de geallieerden overeen om zowel de oostgrens als de westgrens van Polen naar het westen te verschuiven en de rivieren Oder en Neisse als nieuwe grenslijn tussen Duitsland en Polen aan te duiden. Dit had niet alleen immense gevolgen voor de Duitse inwoners van de voormalige Duitse gebieden, maar ook voor grote delen van de Poolse bevolking in het oosten van het land. Gedwongen migratiestromen van Duitsers en Polen richting het westen leidden ertoe dat streken aan beide kanten van de DuitsPoolse grens compleet nieuwe inwoners kregen - mensen die grotendeels onbekend waren met zowel hun nieuwe leefomgeving als de 'nieuwe buren' over de grens. Bovendien werd de rivier door een actieve vervreemding en verdrijvingsaanpak van de Poolse regering tegen de Duitsers het symbool van een strikte scheiding tussen de Duitser aan de ene kant en de Pool aan de andere kant van de Oder. In de zogenaamde 'teruggewonnen gebieden' was 


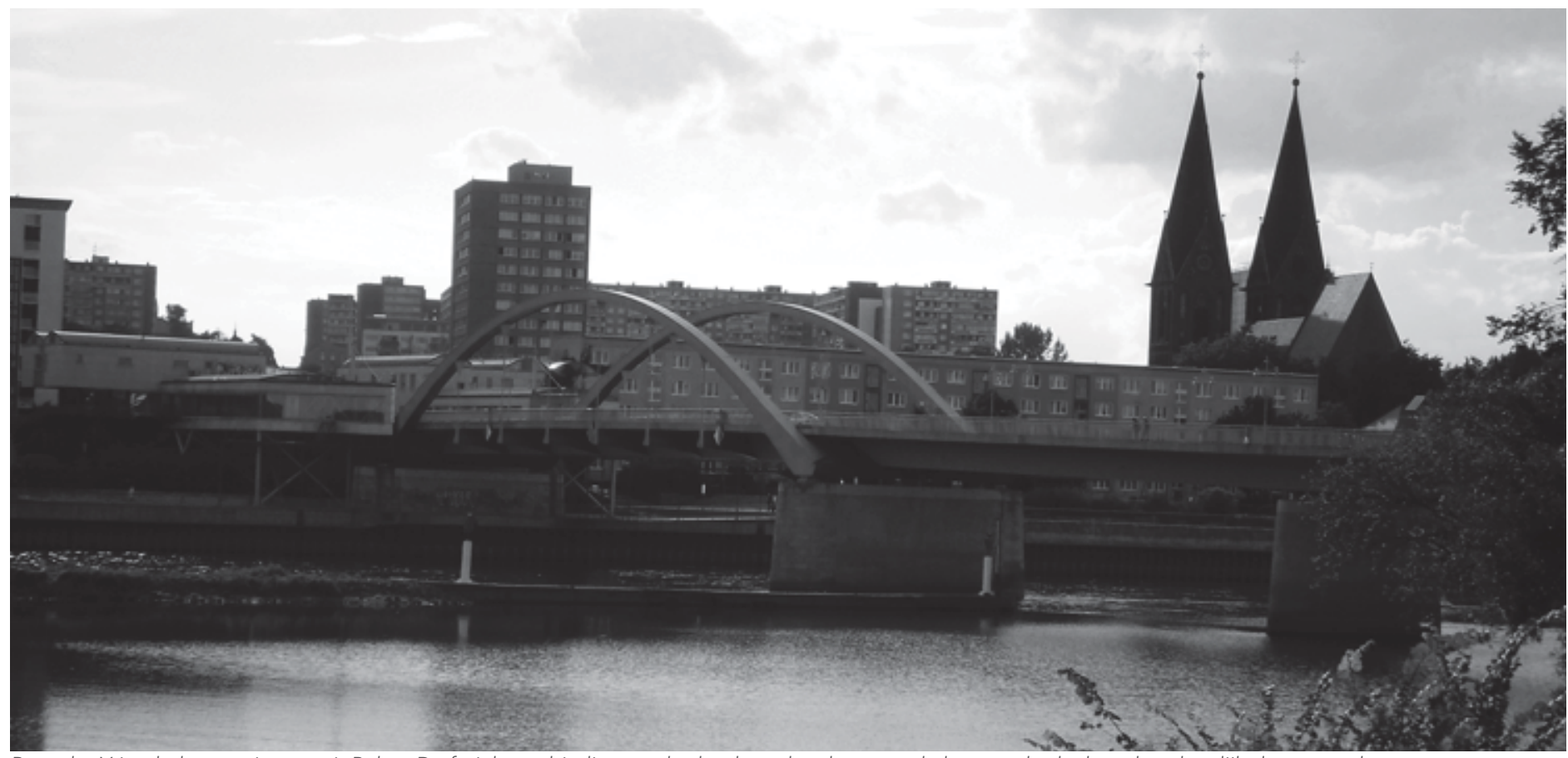

Brug der Vriendschap gezien vanuit Polen. De fysieke verbinding maakt dat de andere kant van de brug onderdeel van het dagelijks leven wordt.

geen plaats voor bewoners van Duitse afkomst. Duitse bewoners werden niet alleen verdreven uit de eigen huizen, maar ook de verschillen tussen Duitsers en Polen werden benadrukt door het Poolse beleid dat sterk gericht was op het versterken van de Poolse nationale identiteit.

Frankfurt-Slubice is niet de enige gescheiden stad aan de DuitsPoolse grens. Ook in Guben-Gubin en Görlitz-Zgrorzelec ligt het stadscentrum aan de ene en de voorstad aan de andere kant van de oever. De impact op de Duitse inwoners van de grenssteden moet enorm zijn geweest; van de ene op de andere dag behoorden de bekende stadsdelen over de Oder toe aan een ander land. De ontoegankelijkheid van de andere kant van de rivier werd destemeer benadrukt door het strikte grensbeleid dat na de oorlog heerste. De vroeger verbonden stadsdelen bevonden zich dichtbij - net over de rivier - maar waren toch ver weg. Dit leidde ertoe dat de steden aan beide kanten van de rivier een eigen dagelijks ritme ontwikkelden, veelal onafhankelijk van de andere kant.

\section{Velen grepen de kans de andere kant van de rivier zelf te ervaren}

Tot de jaren zeventig had de Vriendschapsbrug tussen Frankfurt en Slubice vooral een symbolische functie. Vrije grensovergangen waren er niet, maar eens in de tijd veranderde de brug in een met vlaggen gekleurd middelpunt van officiële festiviteiten ter gelegenheid van de wederzijdse vriendschap tussen de Volksrepubliek Polen en de Duitse Democratische Republiek. Pas in 1972 werd de Vriendschapsbrug een vrije ontmoetingsplaats voor de bewoners van Frankfurt en Slubice. Na meer dan twintig jaar werd het visum afgeschaft en verdween een belangrijke grensbarrière. Deze periode van vrije grensovergang wordt vooral gekenmerkt door nieuwsgierigheid van beide kanten. Beperkte contacten, sterk gecensureerde nieuwsberichten, maar ook herinneringen uit het verleden beïnvloedden de beeldvorming over de andere kant van de grens, maar nu kreeg men de kans om de andere kant van de rivier zelf te ervaren. Een kans die door velen werd gegrepen.

Hoewel de periode van open grenzen in de jaren zeventig maar van korte duur was - uit angst voor de solidariteitsbeweging in Polen sloot de DDR de grenzen met Polen in 1980 - zag deze periode een enorme groei in grensoverschrijdende consumptie, toerisme en vrijetijdsactiviteiten. Bovendien vond in deze jaren ook een toename in grensoverschrijdende arbeid plaats - vooral van Polen die in Oost-Duitsland gingen werken (en zelfs nodig waren) - een trend die zich ook in de jaren tachtig doorzette. Beide stadsdelen waren niet voorbereid op de toename van het dagelijkse grensverkeer. Terwijl winkeliers met betrekking tot voorraad en verkoop rekening moesten houden met klanten van de andere kant van de brug, steeg in deze periode ook de vraag naar restaurants en hotelvoorzieningen aan de Oder.

\section{Zoeken naar een nieuwe balans}

Verwacht werd dat het einde van het communisme tot een hernieuwde toenadering zou leiden tussen de bewoners van Frankfurt en Slubice. Deze leek in eerste instantie echter uit te blijven en was vooral eenzijdig van Poolse kant. In 1991 kwam een eind aan de visa-verplichting en de eerste bewoners van de grenssteden maakten opnieuw kennis met elkaar. In tegenstelling tot de toenadering in de jaren zeventig kwam het grensverkeer niet alleen langzaam op gang, maar was het weerzien niet altijd even vriendschappelijk. Naast bloemen en kreten van vreugde, berichtten de media bijvoorbeeld ook over neonazistische groepen die de Polen 'verwelkomden' met leuzen als "Duitsland zonder Turken, Frankfurt zonder Polen". De brug als verbinding tussen de inwoners van Frankfurt en Slubice 
had niet alleen door de geslotenheid van de grens zijn functie als verbinding verloren, maar ook door de politieke veranderingen in Duitsland na de val van de Berlijnse muur. De Duitse eenwording in 1990 speelde een belangrijke rol in de heroriëntatie naar het westen en het vertrek van veel Duitsers uit het voormalige DDR voor werk, familie, uit angst voor een terugkeer naar het socialisme of simpelweg omdat de mogelijkheid er was. Ook Frankfurt greep de politieke omwenteling aan om zich als een Duitse stad te profileren dat in een herenigd Duitsland thuishoorde. Dit werd onder andere gedaan door de vooroorlogse geschiedenis van Frankfurt als Hanzestad te onderschrijven. Al in 1991 werd de stad voorzien van nieuwe straatnamen die veelal verwezen naar andere Hanzesteden. Straatnamen die verwezen naar Polen, zoals de Warschauer Straße of Zielona Góra Straße die in 1972 feestelijk geïntroduceerd waren, verdwenen uit het straatbeeld.

Zowel de Duitse als de Poolse inwoners van Frankfurt en Slubice verwachtten dat de kansen in het westen lagen. Terwijl de Duitsers naar het westen van Duitsland vertrokken, zochten de Polen naar kansen dichterbij huis. Ondernemers in Slubice richtten zich op Duitse klanten, onder andere met de verkoop van goedkope sigaretten en benzine direct over de Oder en het opzetten van bazaars met een breed aanbod van etenswaren, kleding, sigaretten en zelfs kapsalons.

\section{Grensobservaties}

Tegenwoordig is de brug tussen Frankfurt en Slubice een rustige grensovergang geworden met een voetpad aan weerszijden van de tweebaansweg voor personenauto's. In 2004 is Polen lid geworden van de Europese Unie en sinds de toetreding van Polen tot het Schengengebied in 2007 zijn de douanegebouwen aan de Duitse zijde van de brug niet meer in gebruik. Ondanks dat er af en toe een mobiele douane-eenheid op de brug staat, behoren paspoortcontroles tot het verleden. Doordeweeks wordt de brug regelmatig overgestoken voor een wandeling, een bezoek aan een restaurant of winkel of een benzinestop. Bovendien wordt de grensovergang dagelijks gebruikt door studenten van het Collegium Polonicum in Slubice: een onderwijsinstituut dat door een samenwerkingsverband

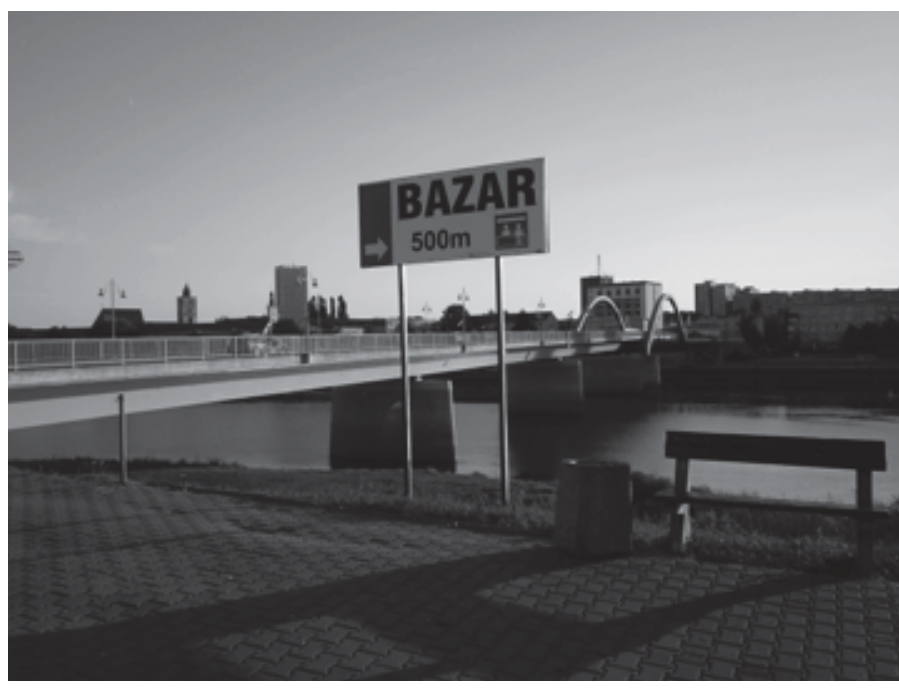

Brug der Vriendschap gezien vanuit Polen. In het weekend bezoeken veel Duitsers uit Frankfurt de bazaars in Polen. tussen de Viadrina Universiteit in Frankfurt en de Adam Mickiewicz Universiteit in Poznan tot stand is gekomen en opleidingen op locaties aan beide zijden van de Oder aanbiedt. Naast studenten zijn er ook speciale klassen voor Poolse scholieren om een gedeelte van de middelbare school in Frankfurt te volgen. In tegenstelling tot de Duitse jongeren, oriënteren jonge Polen zich in grote mate op toekomstmogelijkheden in Duitsland.

\section{Door de verschillen aan beide kanten van de grens kijkt men verder dan de Oder}

In de weekenden is het drukker op de brug, vooral richting de twee bazaars die in Slubice te vinden zijn. Etenswaren, veelal groenten en fruit, kleding en andere 'koopjes' trekken vele Duitsers uit Frankfurt en omstreken aan. Hoewel de prijzen van de kramen grotendeels onderling zijn vastgesteld - en soms niet eens zo veel van de prijzen in Frankfurt verschillen - is er bij de verschillende kramen sprake van een levendige handel tussen de Poolse marktkoopmannen en de Duitse consumenten. Meerdere Duitse reisorganisaties bieden zelfs maandelijkse dagreizen naar de Poolse markten aan, waarbij niet alleen prijsverschillen een rol spelen maar ook vrijetijdsbesteding een belangrijke reden is om met een dergelijke reis mee te gaan. Wat opvalt is dat de voertaal tussen de Polen en Duitsers in zowel Frankfurt als Slubice Duits is. Op de Poolse bazaars en in de kleine hoofdstraat van Slubice worden producten en diensten in het Duits aangeboden - menukaarten in restaurants zijn bijvoorbeeld vertaald naar het Duits en ook kapperszaken presenteren zich als FriseursaIon. In Frankfurt is het echter bijna onmogelijk om in de taal van het buurland te communiceren; op bijvoorbeeld het station, in restaurants, cafés of winkels wordt Duits gesproken en is het als vaak als toerist makkelijker om in het Engels dan Pools te communiceren. Het is de vraag hoe de stadsbrug zich als verbinding in de toekomst zal ontwikkelen. Op lokaal niveau zijn er bijvoorbeeld plannen om een tramverbinding tussen Frankfurt en Slubice te verwezenlijken, terwijl op nationaal niveau Polen over een niet te lange periode tot de Eurogroep lijkt toe te treden. Deze ontwikkelingen kunnen ingrijpende gevolgen hebben voor het grensverkeer tussen de twee stadsdelen.

\section{Stadsbrug als grensoverschrijdende verbinding}

De brug over de Oder is een zichtbare verbinding tussen Frankfurt en Slubice - een brug die doorgaans als stadsbrug wordt aangeduid en de vernieuwde verbondenheid tussen de twee voormalige stadsdelen weergeeft. De stadsbrug is niet zozeer een ontmoetingsplaats voor de bewoners van de twee stadsdelen, maar door de verschillen die de grens met zich meebrengt is de brug cruciaal voor grensoverschrijdende contacten en mobiliteit voor de bewoners in de grensregio en verder. Dagelijkse ontmoetingen tussen bewoners van beide kanten van de brug vinden vooral plaats op de Poolse 


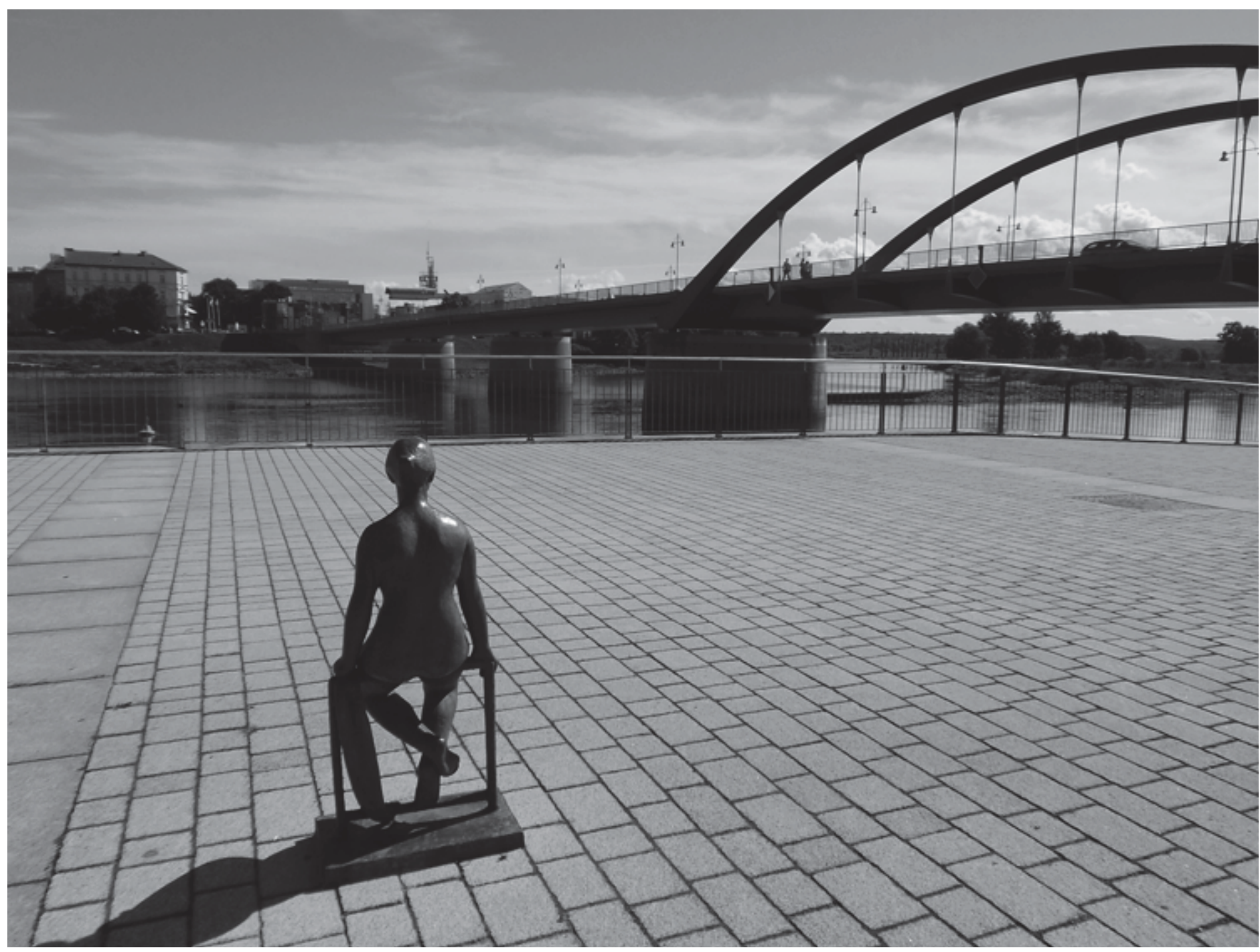

Brug der Vriendschap gezien vanuit Duitsland. Na periodes van onrust, is het tegenwoordig een rustige grensovergang.

bazaars en andere consumptievoorzieningen in Slubice. Terwijl Polen zich richten op de Duitser als consument in Slubice - in het restaurant, het benzinestation, de kapperszaak of op de bazaar - steken Duitsers niet alleen de grens over om van de prijsverschillen te profiteren, maar ook als onderdeel van vrijetijdsbesteding.

De leefomgeving van veel Duitsers en Polen stopt niet bij de brug, maar door de verschillen aan beide kanten van de grens kijkt men verder dan de Oder: volgens Simmel is er sprake van een vergroting van het bereik. Hoewel het bereik in fysieke en sociale ruimte toeneemt, bewaren de bewoners van Frankfurt en Slubice een bepaalde sociale afstand van elkaar. Contacten tussen de bewoners zijn vaak van korte duur en vinden doorgaans plaats in een functionele context in openbare plekken als een bazaar, universiteit of restaurant. Derhalve schept de stadsbrug tussen Frankfurt en Slubice grensoverschrijdende contacten en mobiliteit, maar functioneert de brug meer als een fysieke dan een sociale verbinding tussen de twee stadsdelen aan de Oder.
Bianca Szytniewski (b.szytniewski@uu.nl) is werkzaam bij de Radboud Universiteit Nijmegen en de Universiteit Utrecht. Haar promotieonderzoek richt zich op het begrip 'unfamiliarity' en de rol van bekendheid en onbekendheid in grensoverschrijdende consumptie-activiteiten.

\section{Literatuurselectie}

Fichter-Wolf, H. \& T. Knorr-Siedow (2009) Border Experience and Knowledge Cultures: The Twin Cities of Frankfurt (Oder) and Slubice. disP 178, 7-21.

Gazeta Lubuska Zielona Góra (1952-). Kranten.

Jajesniak-Quast, D. \& K. Stokłosa (2000) Geteilte Städte an Oder und Neiße: Frankfurt (Oder)-Slubice, Guben-Gubin un Görlitz-Zgorzelec, 1945-1995. Berlin: Berlin Verlag.

Krätke, S. (1999) Regional Integration or Fragmentation? The German-Polish Border Region in a New Europe. Regional Studies, $33,631-641$

Neuer Tag (1952-1990) en opvolger Märkische Oderzeitung (1990-) Kranten.

Simmel, Georg (1909) Bridge and Door. In: Frisby, D. \& M. Featherstone ed. (1997) Simmel on Culture: Selected Writings. London: Sage. 